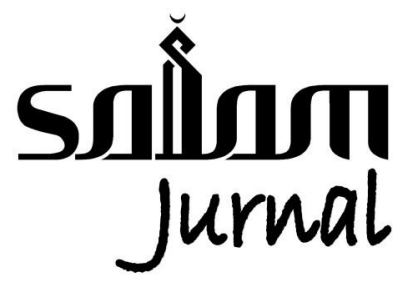

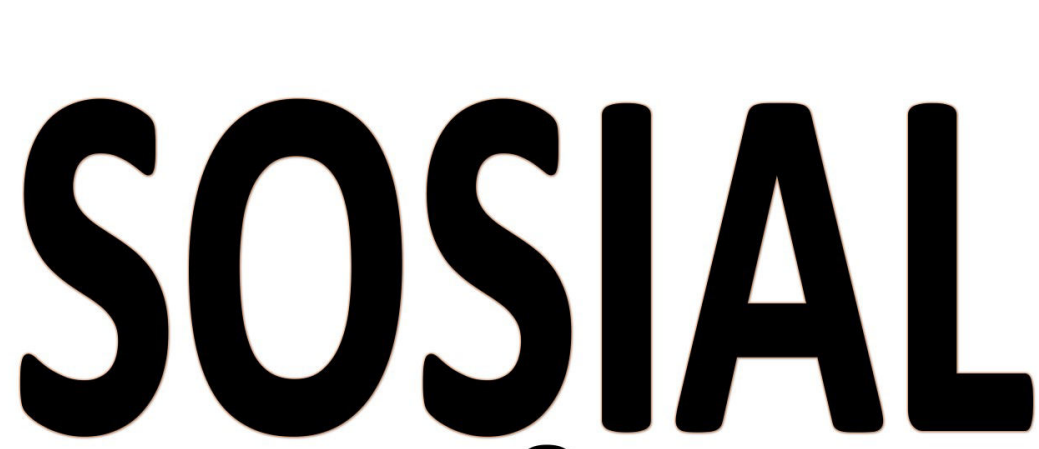

P-ISSN: 2356-1459 E-ISSN: $2654-9050$ Vol. 7 No. 4 (2020)
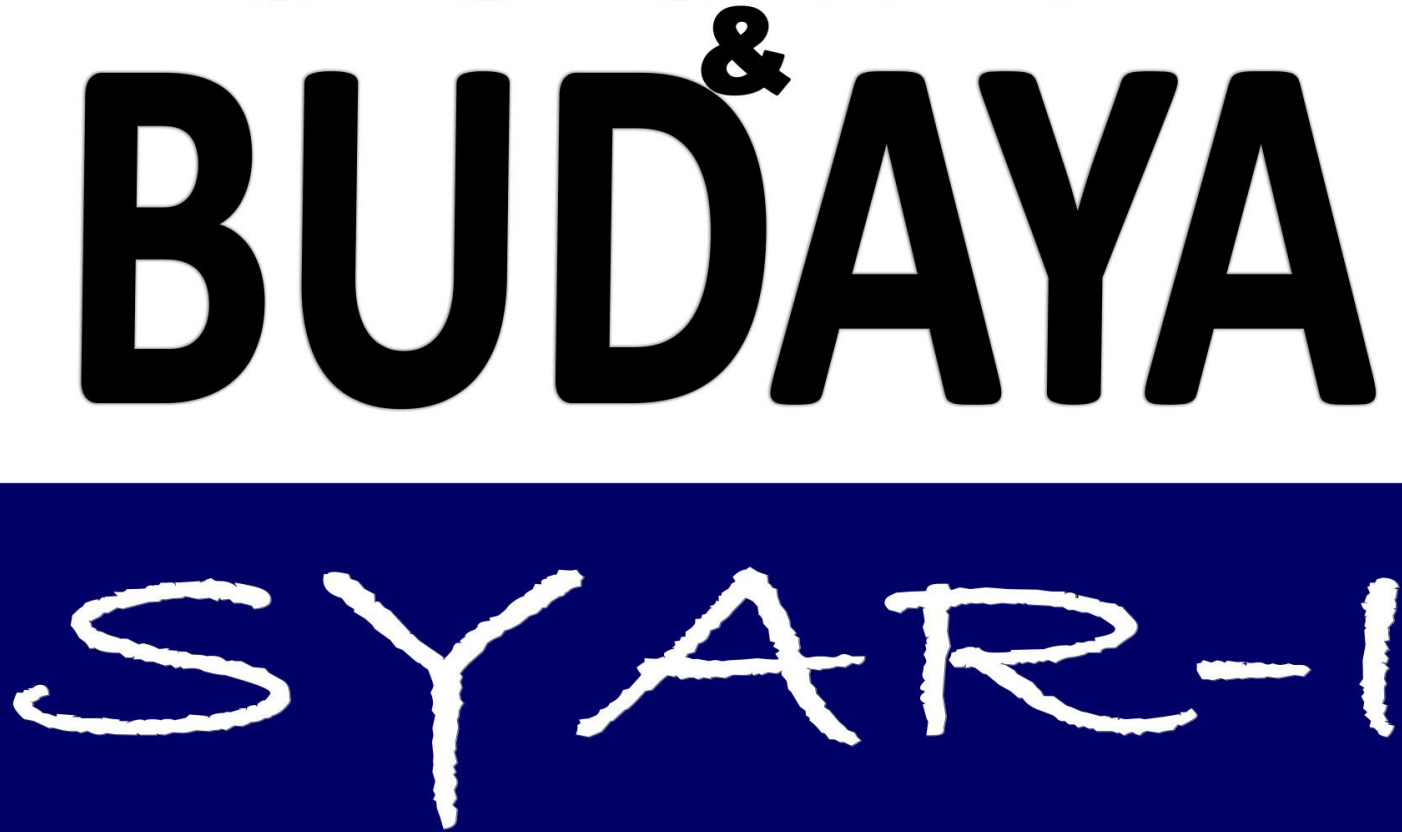

Pesona Tari sebagai Aset Pariwisata Budaya Indonesia

Pupitaning Wulan \& Warih Handayaningrum

Negosiasi Sosiologis Masyarakat Gresik dalam Seni Religi Hadrah

Agni Kusumawati \& Setyo Yanuartuti

Pemuliaan Islam Terhadap Kaum Wanita Dalam Perspektif Alquran dan Hukum Positif

Siti Ngainnur Rohmah

Accounts Payable (Qardh) in Islamic Law

Saprida, Choiriyah \& Melis

Kebijakan Pidana Dalam Pelanggaran Hak Cipta Di Indonesia

Yoyo Arifardhani

Alternatif Penyelesaian Sengketa sebagai Solusi Mewujudkan Asas Pemeriksaan Perkara -

"Sederhana, Waktu Singkat dan Biaya Murah"

Syafrida

Faktor Yang Mempengaruhi Nilai Perusahaan Dengan Corporate Social Responsibility Sebagai -

Variabel Moderating

Senja Nuansari 


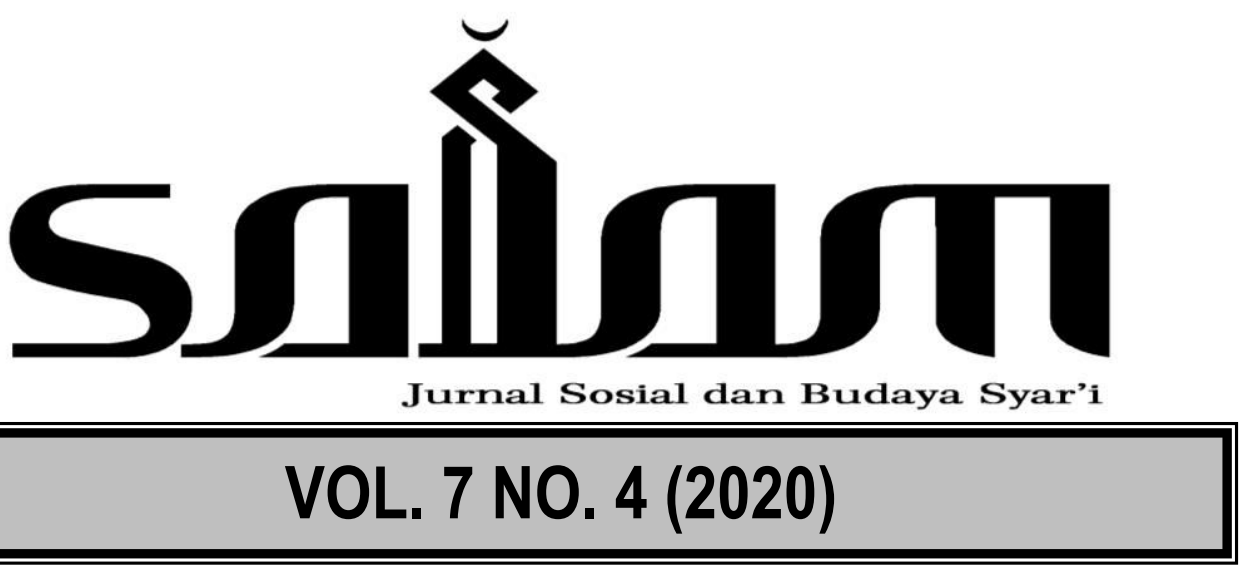

SALAM: Jurnal Sosial Budaya Syar-i (SJSBS) is an open access, and peer-reviewed journal. Our main goal is to disseminate current and original articles from researchers and practitioners on various contemporary social and sharia culture issues. SJSBS is published six times a year. It is nationally accredited by the Ministry of Research, Technology and Higher Education of the Republic of Indonesia (RISTEKDIKTI), No. 30/E/KPT/2019 (November 11, 2019). Submissions are open year-round. Before submitting, please ensure that the manuscript is in accordance with SJSBS's focus and scope and follows our author guidelines \& manuscript template.

SALAM: Jurnal Sosial Budaya Syar-i has become a CrossRef Member since year 2015. Therefore, all articles published by SALAM will have unique DOI number P-ISSN: 2356-1459 - E-ISSN: 2654-9050

\section{Reviewer}

Muhammad Amin Suma (UIN Syarif Hidayatullah Jakarta) A Salman Maggalatung (UIN Syarif Hidayatull ah Jakarta) Asep Saepudin Jahar (UIN Syarif Hidayatullah Jakarta) Ahmad Mukri Aji (UIN Syarif Hidayatullah Jakarta)

JM Muslimin (UIN Syarif Hidayatullah Jakarta)

Muhammad Munir (IIU Islamabad Pakistan)

Euis Amalia (UIN Syarif Hidayatullah Jakarta)

Tim Lindsey (Melbourne University Australia)

Raihanah Azahari (University Malaya Malaysia)

Ahmad Tholabi (UIN Syarif Hidayatullah Jakarta) Ahmad Hidayat Buang (University Malaya Malaysia)

\section{Editor In Chief} Erwin Hikmatiar

\section{Managing Editor}

Indra Rahmatullah

\section{Editors}

Muhammad Ishar Helmi

Mara Sutan Rambe

Nur Rohim Yunus

\section{Assistant to the Editors}

Imas Novita Juaningsih

Azizah Ratu Buana

\section{Alamat Redaksi}

Fakultas Syariah dan Hukum UIN Syarif Hidayatullah Jakarta

J1. Ir. H. Juanda 95 Ciputat Jakarta 15412 Telp. (62-21) 74711537, Faks. (62-21) 7491821 Website: http://journal.uinjkt.ac.id/index.php/salam, E-mail: jurnal.salam@uinjkt.ac.id 


\section{TABLE OF CONTENTS}

\section{3-298}

Pesona Tari sebagai Aset Pariwisata Budaya Indonesia

Pupitaning Wulan \& Warih Handayaningrum

\section{9-310}

Negosiasi Sosiologis Masyarakat Gresik dalam Seni Religi Hadrah

Agni Kusumawati \& Setyo Yanuartuti

\section{1-324}

Pemuliaan Islam Terhadap Kaum Wanita Dalam Perspektif Alquran dan Hukum Positif

Siti Ngainnur Rohmah

\section{5-334}

Accounts Payable (Qardh) in Islamic Law

Saprida, Choiriyah \& Melis

\section{5-352}

Kebijakan Pidana Dalam Pelanggaran Hak Cipta Di Indonesia

Yoyo Arifardhani

\section{3-370}

Alternatif Penyelesaian Sengketa sebagai Solusi Mewujudkan Asas

Pemeriksaan Perkara "Sederhana, Waktu Singkat dan Biaya Murah"

Syafrida

\section{1-394}

Faktor Yang Mempengaruhi Nilai Perusahaan Dengan Corporate Social Responsibility sebagai Variabel Moderating

Senja Nuansari 


\title{
Negosiasi Sosiologis Masyarakat Gresik dalam Seni Religi Hadrah*
}

\author{
Agni Kusumawati, ${ }^{1}$ Setyo Yanuartuti $^{2}$ \\ Pascasarjana Pendidikan Seni Budaya, Program Pascasarjana, \\ Universitas Negeri Surabaya \\ 10.15408/sjsbs.v7i4.15204
}

\begin{abstract}
Culture that develops in society is a reflection of social society and community assessment. One form of culture is art. In the Gresik community, its development lies in Islamic religious art, so the developing arts also adapt Islamic religion to Hadrah's religious art forms. The existence of Hadrah in society is a shared responsibility, which is seen from the public awareness of the growth of Hadrah's religious arts. This study discusses the sociological negotiations of the Hadrah Art of Religion on the development and growth of the Gresik community. This research included content analysis research on how Hadrah's religious arts influenced economic, cultural and educational aspects in Gresik, East Java, Indonesia. The sociological point of view of Homi K. Babha is used to see the development and continuity of Hadrah's religious arts that negotiate with the community so that they can contribute to it. The results of the study show that to maintain the existence of the Gresik community, an awareness is maintained to continue to support and recognize the present presentation of the religious arts of Hadrah. Besides through approaches to support and recognize Hadrah's religious arts, they also try to find out how the history of Hadrah's religious art is found in the Gresik community. By knowing the existence of Hadrah's religious art and how it is known to the public, it will help to add appreciation to Hadrah's religious art. The religious art of Hadrah and its presidents is expected to be able to create the present Hadrah religious art innovations that reflect without leaving the form of presentation of Hadrah's religious art. Keywords: Sociological View, Hadrah's Religious Art, Gresik Society
\end{abstract}

\begin{abstract}
Abstrak
Kebudayaan yang berkembang pada masyarakat merupakan cermin dari sosial masyarakat dan penilaian masyarakat. Salah satu wujud dari kebudayaan adalah kesenian. Di masyarakat Gresik, perkembangannya terletak pada seni religi Islami, maka kesenian yang berkembang pun juga menyadur religi Islami dengan bentuk seni religi Hadrah. Keberadaan Hadrah pada masyarakat merupakan tanggung jawab bersama, yang dilihat dari kesadaran masyarakat terhadap pertumbuhan seni religi Hadrah. Penelitian ini membahas tentang negosiasi sosiologis Seni Religi Hadrah terhadap perkembangan dan pertumbuhan masyarakat Gresik. Penelitian ini termasuk penelitian analisis konten tentang bagaimana seni religi Hadrah memengaruhi aspek ekonomi, budaya, dan pendidikan di Gresik, Jawa Timur, Indonesia. Sudut pandang sosiologis milik Homi K. Babha dipakai untuk melihat perkembangan dan kontinuitas seni religi Hadrah yang bernegosiasi dengan masyarakat sehingga mampu berkontribusi di dalamnya. Hasil penelitian menunjukkan bahwa untuk menjaga eksistensi pada masyarakat Gresik diperlakukan kesadaran untuk tetap mendukung
\end{abstract}

*Diterima: 18 Maret 2020, Revisi: 20 Maret 2020, Diterbitkan 4 April 2020.

${ }^{1}$ Agni Kusumawati adalah guru dan mahasiswa Pascasarjana Pendidikan Seni Budaya, Program Pascasarjana, Universitas Negeri Surabaya. E-mail: kusumawatiagnii@gmail.com

2 Setyo Yanuartuti adalah adalah Doktor dan pengajar di Program Pascasarjana Pendidikan Seni Budaya, Program Pascasarjana, Universitas Negeri Surabaya. 
dan mengenal penyajian seni religi Hadrah saat ini. Selain melalui pendekatan untuk mendukung dan mengenal seni religi Hadrah, namun juga berusaha mengetahui bagaimana sejarah seni religi Hadrah yang terdapat pada masyarakat Gresik. Dengan mengetahui keberadaan seni religi Hadrah dan bagaimana ia dikenal masyarakat, maka akan turut membantu menambah apresiasi terhadap seni religi Hadrah. Seni religi Hadrah dan para pelestarinya diharapkan mampu menciptakan inovasi seni religi Hadrah kekinian yang bercermin tanpa meninggalkan bentuk penyajian seni religi Hadrah.

Kata Kunci: Negosiasi Sosiologis, Seni Religi Hadrah, Masyarakat Gresik

\section{Pendahuluan}

Kesenian adalah bagian dari budaya dan merupakan sarana yang digunakan untuk mengekspresikan rasa keindahan dari dalam jiwa manusia. Selain mengekspresikan rasa keindahan dari dalam jiwa manusia, kesenian juga mempunyai fungsi lain. Misalnya, mitos berfungsi menentukan norma untuk perilaku yang teratur serta meneruskan adat dan nilai-nilai kebudayaan. Secara umum, kesenian dapat mempererat ikatan solidaritas suatu masyarakat. ${ }^{3}$

Tari di masyarakat ditentukan oleh masyarakat dapat diamati melalui adanya kesadaran masyarakat dalam berkesenian melalui media gerak. ${ }^{4}$ Pertumbuhan tari pada masyarakat dapat berlangsung apabila terdapat hubungan antara tari dengan kesadaran masyarakat. Kesenian atau tari didekati atau ditinjau dari sosiologi, berusaha menghubungkan kesenian itu dengan struktur sosialnya. ${ }^{5}$ Kesenian atau tari termasuk sistem simbol atau nilai dan ideologi, sedangkan kesadaran kolektif atau struktur sosial. Dengan demikian untuk mempelajari sosiologi seni atau tari berusaha menghubungkan 'sistem simbol' dan 'sistem sosial'.6

Keberadaan seni religi Hadrah pada masyarakat dapat mencapai pertumbuhan apabila masyarakat menerima simbol yang ada dalam seni religi Hadrah melalui penghayatan. Penghayatan masyarakat terhadap seni religi Hadrah mempunyai fungsi tertentu, sebab selain seni religi Hadrah sebagai bentuk kesenian seni religi Hadrah juga sebagai sarana: 1) perjuangan dalam upacara kepercayaan siklus dari hidup manusia; 2) hubungan manusia dengan manusia; dan 3) hubungan masyarakat dengan masyarakat. Struktur sosial dalam masyarakat membuat keseluruhan jalinan antara unsur-unsur sosial yang ada dalam masyarakat. Struktur sosial yang ada dalam masyarakat menyatakan bahwa struktur sosial terdiri dari norma-norma sosial, lembaga sosial dan kelompok serta lapisan masyarakat.7

${ }^{3}$ Edmund Burke Feldman, Art as Image and Idea (New Jersey: Prentince Hall, 1967); Diane Barthel, “Historic Preservation : A Comparative Analyses," Sociological Forum 4, no. 1 (1989): 87-105.

${ }^{4}$ Yulianti Parani, Penari Sebagai Sumber Daya Dalam Penataan Tari (Jakarta: Departemen Pendidikan dan Kebudayaan, 1986); Anya Peterson Royce, Antropologi Tari (Bandung: Sunan Ambu Press, 2007).

${ }^{5}$ A.G. Muhaimin, “The Ritual Practice : Ibadat," in The Islamic Traditions of Cirebon (Indonesia: ANU Press, 2006).

${ }^{6}$ C. J. Hawkesworth et al., “A Matter of Preservation,” Science 323, no. 5910 (2009): 49-50, http://www.sciencemag.org/cgi/doi/10.1126/science.1168549.

7 Perla Innocenti, "Preventing Digital Casualties: An Interdisciplinary Research for Preserving Digital Art," Leonardo 45, no. 5 (2012): 472-473; Paul Conway, "Preservation in the Age of Google: 
Keberadaan seni religi Hadrah pada masyarakat mempunyai fungsi dalam kehidupan masyarakat untuk kesejahteraan hidup sebagai masyarakat budaya. Sesuatu dengan pernyataan yang mengatakan bahwa seni religi mempunyai arti terpenting dalam fungsi tertentu dalam kehidupan kebudayaan masyarakat seperti dalam berbagai upacara kepercayaan siklus dari pada manusia, hubungan manusia dan manusia atau masyarakat dengan masyarakat. ${ }^{8}$ Pentingnya keberadaan seni religi Hadrah pada masyarakat untuk kesejahteraan dan wujud dari budaya, maka dalam penelitian ini perlu adanya kesadaran dari individu atau kelompok masyarakat untuk menjaga dan melestarikan seni religi Hadrah yang terdapat pada lingkungan setempat.

Kepedulian individu atau kelompok masyarakat menentukan pertunjukan tari, yang dilakukan oleh masyarakat dengan jalan menjalani keakraban. ${ }^{9}$ Dengan keakraban akan memberi bentuk seni budaya masyarakat yang tradisi, sebab sifat seni budaya masyarakat kita banyak mencerminkan situs keagamaan dan bentuk yang beragam. Dengan begitu seni mencerminkan kehidupan masyarakat. Hal ini sesuai pernyataan dalam seni tradisi, di mana kesenian yang paling tradisional terjadi karena sifat keakraban masyarakat pertanian dan wajah seni yang sangat akrab, ${ }^{10}$ artinya homogenisasi serta tingkat yang sangat intensif dari interelasi di dalam kosmos kerajaan kecil itulah, yang memberikan bentuk serta sifat seni budaya dalam sistem masyarakat tradisional. Ia terjalin rapat dengan segala situs keagamaan dan obligasi kemasyarakatan yang beraneka ragam seperti menjadi denyut nadi masyarakat itu. ${ }^{11}$ Keberadaan kesenian pada masyarakat mencapai pertumbuhan apabila terdapat kepedulian masyarakat terhadap kesenian tersebut. Seperti halnya keberadaan seni religi Hadrah pada masyarakat Gresik, selama ini hanya individu dan masyarakat tertentu yang mengetahui keberadaan seni religi Hadrah. Pada kenyataan seni religi Hadrah mempunyai fungsi ganda, selain bentuk seni juga sebagai sarana individu dan masyarakat dalam lingkungan kecil kerajaan. Gejala terbatasnya individu dan kelompok yang mengetahui keberadaan seni religi Hadrah, maka perlu adanya langkah pengenalan pada masyarakat Gresik pada seni religi Hadrah. Dengan tujuan agar seni religi Hadrah tetap memiliki eksistensi pada masyarakat dan untuk menjaga kelestarian kesenian tradisi.

Penelitian ini membahas tentang negosiasi sosiologis Seni Religi Hadrah terhadap perkembangan dan pertumbuhan masyarakat Gresik. Cakupan bahasan dalam penelitian ini adalah 1) fenomena yang dapat mempengaruhi pertumbuhan seni religi Hadrah di Kabupaten Gresik; dan 2) upaya yang dilakukan untuk mendukung pertumbuhan seni religi Hadrah di Kabupaten Gresik.

Digitization , Digital Preservation , and Dilemmas," The Library Quarterly: Information, Community, Policy 80, no. 1 (2015): 61-79.

${ }^{8}$ Parani, Penari Sebagai Sumber Daya Dalam Penataan Tari.

${ }_{9}$ Royce, Antropologi Tari.

${ }^{10}$ Umar Kayam, Seni, Tradisi, Masyarakat (Jakarta: Sinar Harapan, 1981).

${ }^{11}$ Ibid. 


\section{Metode Penelitian}

Penelitian ini merupakan penelitian etnografi yang mempelajari secara mendalam salah satu nilai-nilai budaya yang terjadi dalam masyarakat Gresik yaitu seni religi Hadrah. Esensi dari penelitian ini adalah memahami secara mendalam tentang ciri-ciri dan fungsi seni religi Hadrah dalam masyarakat Gresik. Agar peneliti terhindar dari bias etnosentrisme dan dapat melukiskan dalam thick description maka perlu menggunakan sudut pandang. Di dalam penelitian ini, peneliti menggunakan sudut pandang sosiologis milik Homi K. Babha. Selain itu, digunakan pula perspektif etik dengan mendeskripsikan kebudayaan berdasarkan sudut pandang peneliti dengan konsep-konsep antropologis. ${ }^{12}$ Dengan demikian, melalui penelitian ini maka akan dapat dilihat secara mendalam nilai-nilai sosial budaya masyarakat Gresik dan faktor pendukung pelestarian seni religi Hadrah. Peneliti telah berada di lapangan selama 6 bulan, yaitu sejak Juli 2019 hingga Januari 2020. Selama masa itu penulis mengumpulkan data dengan cara menerapkan metode penelitian observasi parsitipatif (participant obeservation), yang dilengkapi dengan metode wawancara mendalam.

Data yang dicari terlebih dahulu adalah seni religi Hadrah yang berkaitan dengan sejarah, pertumbuhannya, serta penyajiannya pada masyarakat Gresik. Setelah mengetahui keberadaannya pada masyarakat yang disertai pengamatan dan pencatatan, maka penulis lanjut dengan memperhatikan penyajian seni religi Hadrah. Selanjutnya seni religi Hadrah ditulis dalam bentuk penyajian ilmiah dengan sudut pandang sosiologi seni yang sesuai dengan permasalahan. Untuk mencari data narasumber, wawancara secara langsung untuk mendapatkan data yang akurat dan aktual wawancara dilakukan pada Lembaga Budaya untuk mendapatkan data tentang keberadaan seni religi Hadrah, serta kesadaran masyarakat terhadap seni religi Hadrah.

\section{Hasil dan Pembahasan}

Seni religi Hadrah adalah bentuk karya seni yang terdapat unsur gerak yang disebut rodat. Maka dari itu seni religi Hadrah identik dengan tari. Pertumbuhan seni religi Hadrah bersifat monoton dan berkembang pada masyarakat homogen. Ironisnya, masyarakat yang berkembang di Gresik bersifat heterogen. ${ }^{13}$ Dengan begitu keberadaan seni religi Hadrah pada masyarakat hanya masyarakat tertentu yang mengetahuinya. Pendukung seni religi Hadrah mempunyai tujuan dan penyajian yaitu silaturahmi dan melaksanakan haul yang merupakan peringatan hari wafat seseorang yang diadakan setahun sekali dari pemuka agama, sedangkan masyarakat sekitar ada yang tidak peduli terhadap keberadaan seni religi Hadrah.

Berkaitan dengan unsur tari dalam seni religi Hadrah, penyebab luar pada kehidupan tari adalah keadaan-keadaan sosial ekonomi pada setiap seniman yang

\footnotetext{
${ }^{12}$ Heddy Shri Ahimsa-Putra, Epistemologi Antropologi (Yogyakarta: Universitas Gadjah Mada Press, 1995); Latif Wiyata, Carok Konflik Kekerasan Dan Harga Diri Orang Madura (Yogyakarta: LKIS, 2006).

${ }^{13}$ Julian Millie, "Supplicating, Naming, Offering: 'Tawassul' in West Java," Journal of Southeast Asian Studies 39, no. 1 (2008): 107-122.
} 
secara perorangan mempunyai tuntutan dan cara-cara sendiri. ${ }^{14}$ Pengaruh dari masyarakat sangat mempengaruhi dan membatasi, bahkan memutar balikkan adannya bakat yang kreatif meskipun juga memberi kesenangan yang bersifat terbuka, dapat memutar balikkan arah yang mengganggu karena tidak menguntungkan, sehingga kurang dianggap menyenangkan. ${ }^{15}$ Dalam pertumbuhan tari bukan saja diperlukan hasil karya yang bagus, tetapi juga perlu adanya dukungan dari masyarakat sekitar. Selain itu dalam pertumbuhan juga mengalami bermacam-macam dan perlu pemikiran untuk pertumbuhan tari, yang dipengaruhi oleh keadaan sosial masyarakat. ${ }^{16}$

Diperjelas bahwa pertumbuhan tari juga perlu adanya penyelesaian melalui pendekatan dari berbagai segi, seni pada masyarakat Gresik dapat mencapai pertumbuhan apabila terdapat pendekatan terhadap budaya yang berkembang pada masyarakat dan perubahan sosial masyarakat. Sesuai pernyataan Royce bahwa tari telah mengalami nasib yang bermacam-macam ditangan pakar-pakar antropologi dalam seratus tahun terakhir. ${ }^{17}$ Oleh karenanya unsur dalam Hadrah berkembang. Hal tersebut membuat seni religi Hadrah dituntut untuk mengalami perkembangan dan proses pelestarian dalam masyarakat saat ini namun masih tetap menunjukkan identitas budaya masyarakat Gresik.

Homi K. Bhabha dalam The Location of Culture berpendapat bahwa identitas budaya bukanlah identitas bawaan yang sudah diberikan sejak lahir dari kekosongan. ${ }^{18}$ Identitas kultural bukan entitas yang ditakdirkan yang tidak mampu direduksi, atau ciri ahistoris yang menetapkan konvensi kultural. Sepertihalnya tentang pandangan oposisi biner antara "penjajah" dan "terjajah" tidak lagi sebagai sesuatu yang terpisah satu dari yang lainnya dan masing-masing berdiri sendiri. Negoisasi kultural mencakup perjumpaan dan pertukaran tampilan budaya berifat kontinyu yang pada saatnya akan menghasilkan pengalaman timbal balik akan perbedaan budaya. ${ }^{19}$ Bahwa bukan hanya yang terjajah yang mengambil atau meniru kaum penjajah, dalam beberapa hal kaum penjajah pun mengambil atau meniru dari kaum terjajah walaupun dalam porsi yang lebih sedikit.

Bhabha menegaskan bahwa baik penjajah maupun terjajah tidak independen satu sama lain. ${ }^{20}$ Relasi-relasi kolonial itu distrukturkan oleh bentuk-bentuk kepercayaan yang beraneka dan kontradiktif. Menurut Bhabha, antara penjajah dan terjajah terdapat "ruang antara" yang memungkinkan keduanya untuk bernegosiasi. ${ }^{21}$

14 M. Dawam Rahardjo, "Perceptions of Culture in the Islamic Movement: An Indonesian Perspective," Journalof Social Issues in Southeast Asia 7, no. 2 (1992): 248-273; Muhaimin, "The Ritual Practice : Ibadat."

${ }^{15}$ Nicholas M. Pace and Laura Zakaras, The Challenges of Preservation Book (RAND Corporation, 2013); Millie, "Supplicating, Naming, Offering: 'Tawassul' in West Java."

${ }^{16}$ Peter L Thorslev, "Preservation, Contemporary Art, and Architecture," Future Anterior: Journal of Historic Preservation, History, Theory, and Criticism 4, no. 2 (2007): 70-85; Manijeh Mannani, “The Metaphysics of the Heart in the Sufi Poetry of Rumi," Religion and Literature 42, no. 3 (2019): 161-168.

17 (2007)

${ }^{18}$ Homi K. Bhabha, The Location of Culture (London: Routledge, 1994).

${ }^{19}$ Ibid.

${ }^{20}$ Ibid.

${ }^{21}$ Ibid. 
Di antara keduanya terdapat ruang yang longgar untuk suatu resistensi. Maka dari itu, seni religi Hadrah memiliki ruang bagi penikmat, pemerhati, dan pelestarinya untuk turut serta menjadi bagian budaya masyarakat Gresik. Begitu pula dengan masyarakat Gresik, yang menjadi instrumen utama dalam proses pelestarian dan pertunjukan seni religi Hadrah. Batasan-batasan yang ada, dengan konsep liminalitas Bhabha digunakan untuk mendeskripsikan suatu "ruang antara" di mana perubahan budaya berlangsung. Ruang antarbudaya merupakan tempat di mana strategi-strategi kedirian personal maupun komunal dapat dikembangkan. ${ }^{22}$ Dapat dilihat pula sebagai suatu wilayah di mana terdapat proses gerak dan pertukaran antara status yang berbeda-beda yang terus menerus.

Pencarian identitas itu idealnya tidak pernah berhenti, identitas mengalir sebagai sesuatu yang senantiasa mengalami proses perubahan. Bhabha melukiskan bagaimana budaya-budaya itu bergerak keluar masuk ruang ketiga sebagai tempat bernegosiasi. ${ }^{23}$ Teori liminalitas Bhabha ini memang mengesankan menghindari oposisi biner yang konfrontatif atau saling menaklukkan. ${ }^{24}$ Sebaliknya, yang hendak ditawarkan Bhabha adalah bahwa ruang ambang itu mampu berperan sebagai ruang untuk interaksi simbolik yang dengan demikian memberikan kontribusi penting bagi pemahaman perbedaan budaya. ${ }^{25}$

Dalam kajian ilmu sosial, kemudian ada upaya memformulasikan konsep fisikal identitas secara lebih dinamis. Satu faktor yang mendorong perumusan baru terhadap konsep identitas adalah banyaknya konflik sosial, politik, dan kebudayaan yang mengekspose dan mengeksploitasi perbedaan. ${ }^{26}$ Di samping itu ketika perkembangan dunia semakin mengglobal, maka mobilitas sosial, migrasi penduduk, perdagangan bebas, lintas batas, dan serba berjejaring, maka problem identitas menjadi semakin kabur. Karena itu identitas tidak ada yang bersifat tetap dan mengkristal. ${ }^{27}$ Penelusuran terhadap makna dan konsep identitas pun merupakan suatu usaha berkelanjutan tanpa akhir. Oleh karena itu identitas bukan merupakan suatu entitas konstruksi dasar atau spiritual yang final dan statis, melainkan sesuatu yang selalu tumbuh dan relasional. Sejalan dengan ungkapan Hall yang menyebutnya sebagai suatu yang tidak pernah sempurna, selalu dalam proses dan selalu dibangun dari dalam..$^{28}$ Masyarakat Gresik meletakkan identitas diri sebagai pelopor seni religi Hadrah yaitu sebagai "primordial" merujuk pada anggapan bahwa etnisitas adalah sebuah identitas yang dibawa seseorang sejak lahir. Maka dari itu, sebenarnya masyarakat Gresik telah membuka ruang bagi masyarakat luas dalam proses pelestaria seni religi Hadrah dan eksistensinya saat ini.

Seni religi Hadrah yang memiliki identitas budaya sebagai seni yang berkaitan dengan agama memiliki batas-batas yang jelas. Geertz memberi batasan pengertian

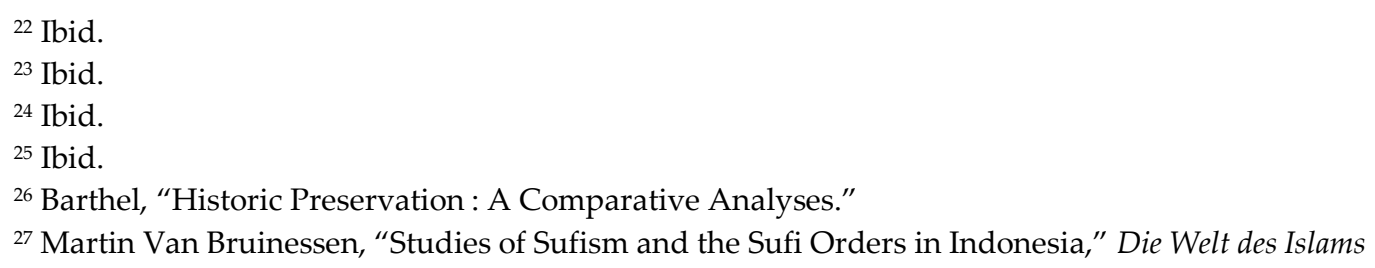


agama sebagai berikut; agama merupakan sistem simbol yang bertindak untuk menetapkan perasaan dan motivasi yang kuat, meluas, dan awet dalam diri manusia dengan cara memformulasikan konsep-konsep tentang tatanan umum keberadaan atau eksistensi dan mengisi konsep-konsep tersebut dengan aura faktualitas sehingga perasaan dan motivasi tersebut tampak secara khusus, unik, dan nyata. ${ }^{29}$ Batasan agama yang diungkapkan Geertz ini dirasa tepat bagi studi ini karena didalamnya tidak terkandung elemen-elemen keilahian (wahyu), dan sejenisnya; melainkan agama didekati sebagai suatu gejala sosial-budaya yang mewujud dalam berbagai sistem simbol. Lebih lanjut, sebagai sebuah sistem, Koentjaraningrat memandang agama sebagai sebuah sistem yang terdiri dari empat usur dasar. Keempat unsur dasar tersebut adalah; emosi keagamaan, sistem kepercayaan, sistem upacara, dan kelompok keagamaan. ${ }^{30}$ Keempat unsur dasar tersebut harus ada, agar suatu fenomena dapat dipahami sebagai agama. Lebih lanjut Koentjaraningrat mengemukakan bahwa sistem upacara dan juga seni religi melibatkan sejumlah unsur, termasuk tindakan, peralatan, tempat, waktu, maupun pelaku (pemimpin dan umat). ${ }^{31}$

Untuk menciptakan kehidupan yang lebih baik maka manusia menciptakan sesuatu untuk memenuhi kebutuhan batin yang disebut dengan kebudayaan yang bersifat bebas, meskipun kebudayaan bersifat bebas tetapi masih ada keterikatan dengan masyarakat sekitar. Contohnya adalah bagaimana keadaan seni religi Hadrah pada masyarakat, menurut pernyataan JWM Bakker bahwa kebudayaan menyinggung daya cipta bebas dan serba ganda dari manusia dalam dunia. ${ }^{32}$ Salah satu wujud dari kebudayaan itu dapat dilihat melalui keberadaan seni religi Hadrah pada masyarakat Gresik dan masing-masing wilayah memiliki perbedaan dalam pertumbuhan tari. Permasalahan kebudayaan pada masyarakat menurut Kebudayaan dan sistem religi Indonesia adalah suatu kondisi majemuk karena ia bermodalkan berbagai kebudayaan lingkungan wilayah yang berkembang menurut tuntutan sejarahnya sendiri-sendiri. ${ }^{33}$ Pengalaman serta kemampuan wilayah itu memberikan jawaban terhadap masingmasing tentangan itulah yang memberikan bentuk dari kebudayaan itu. Juga proses sosiologi yang kemudian dikembangkan dalam kerangka masing-masing kultur itu memberikan warna kepada kepribadian yang muncul dari lingkungan wilayah budaya itu. ${ }^{34}$ Sesuai pernyataan Umar Kayam (1981) setiap wilayah memiliki kebudayaan yang sesuai dengan sejarah masyarakat setempat, ${ }^{35}$ dengan begitu memberikan warna sosial masyarakat pada karya seni.

Masyarakat dan individu merupakan salah satu komponen bahkan komponen utama dalam tari karena dalam berkesenian merupakan pelaku tari yang berkedudukan sebagai pencipta untuk menghasilkan karya tari, penari merupakan individu atau

${ }^{29}$ Clifford Geertz, The Interpretation of Cultures (New York: Basic Book, 1973).

${ }^{30}$ Koentjaraningrat, Sejarah Teori Antropologi (Jakarta: UI Press, 1987); Koentjaraningrat, Pengantar Antropologi (Pokok-Pokok Etnografi) II (Jakarta: Rineka Cipta, 1998).

${ }^{31}$ Koentjaraningrat, Pengantar Antropologi (Pokok-Pokok Etnografi) II.

${ }^{32}$ JWM Bakker, Filsafat Kebudayaan Sebuah Pengantar (Yogyakarta: Pustaka Filsafat Kanisius, 1984).

${ }^{33}$ Kayam, Seni, Tradisi, Masyarakat.

${ }^{34}$ Sheila Lintott, "Preservation, Passivity, and Pessimism," Ethics and the Environment 16, no. 2 (2011): 95-114.

${ }^{35}$ Kayam, Seni, Tradisi, Masyarakat. 
kelompok yang memberikan simbol dan penghayatan sebagai penerima simbol yang kemudian diberikan penilaian. ${ }^{36}$ Dengan kata lain kesadaran untuk melakukan tari dilakukan oleh seniman yang menciptakan tari, penari sebagai seniman yang melakukan gerak dan penghayat melihat pertumbuhan atau sebagai penonton. Selain itu, pemacu pertumbuhan tari selain individu dan masyarakat memerlukan dukungan dari pemerintah dan orang yang lebih tahu tentang kesenian yang terdapat pada lingkungan masyarakat setempat terhadap keberadaan tari. ${ }^{37}$

Usaha penyelamatan tradisi seni religi Hadrah ini harus mendapat apresiasi karena di dalamnya memiliki bentuk ekspresi kebudayaan daerah yang hadir di tengahtengah masyarakat pemiliknya. Hal tersebut dikarenakan dalam seni religi Hadrah mengandung nilai-nilai yang patut diteladani seperti kepercayaan, pandangan hidup, cara berpikir, dan nilai budaya bangsa yang mempunyai hubungan erat dengan kehidupan masyarakat pemiliknya, baik dalam hubungan dengan masa lalu, masa sekarang, maupun masa yang akan dating. ${ }^{38}$

Dalam pandangan Ahimsa-Putra tradisi dan seni religi merupakan salah satu kearifan lokal yang tersimpan dalam karya-karya lokal, baik lisan maupun tertulis, bisa juga dikatakan sebagai cermin dari masyarakat pemiliknya, ${ }^{39}$ sehingga mempelajari tradisi dan seni religi, mulai dari mantra, pantun, peribahasa, hingga cerita rakyat akan sangat membantu memahami pola pikir atau berbagai kejadian dalam kehidupan masyarakat. ${ }^{40}$ Terdapat hubungan antara tradisi dan seni religi dengan kebudayaan, sebab tradisi dan seni religi merupakan salah satu unsur kebudayaan, sehingga tradisi dan seni religi bagi para ahli antropologi dapat dipahami sebagai data kebudayaan yang mengandung berbagai informasi tentang kebudayaan. Sebagai salah satu data kebudayaan, bahwa tradisi dan seni religi dapat dipandang sebagai 'pintu masuk' untuk memahami kebudayaan itu sendiri. ${ }^{41}$ Maka posisi tradisi dan seni religi dapat menjadi unsur-unsur kebudayaan seperti sistem nilai, sistem politik, sistem kepercayaan, sistem mata pencaharian, dan sebagainya. Berkaitan dengan hal tersebut, sudut pandang Malinowski mendukung dengan mengemukakan bahwa fungsi dari satu unsur kebudayaan adalah kemampuannya untuk memenuhi kebutuhan dasar atau beberapa kebutuhan yang timbul dari kebutuhan dasar, yaitu kebutuhan sekunder dari pada warga dari suatu masyarakat. ${ }^{42}$

Setelah menjadi salah satu budaya setempat, ada beberapa faktor yang memengaruhi pertumbuhan seni religi Hadrah pada masyarakat Gresik, yaitu masyarakat pendukung, yang merupakan keseluruhan anggota yang tergabung dalam penyajian seni religi Hadrah, menyatunya masyarakat pendukung dalam satu

${ }^{36}$ Sean Mallon, “Against Tradition,” The Contemporary Pacific 22, no. 2 (2010): 362-381.

37 Ibid.

${ }^{38}$ Hawkesworth et al., "A Matter of Preservation."

${ }^{39}$ Ahimsa-Putra, Epistemologi Antropologi.

${ }^{40}$ David Carrier, "Art and Its Preservation," The Journal of Aesthetics and Art Criticism 43, no. 3 (2006): 291; Hawkesworth et al., "A Matter of Preservation."

${ }^{41}$ Ahimsa-Putra, Epistemologi Antropologi.

${ }^{42}$ Malinowski, A Scientific Theory of Culture and Other Essays (New York: Oxford University Press, 1944); Koentjaraningrat, Sejarah Teori Antropologi. 
hubungan akan mewujudkan jalinan antara individu dan kelompok. ${ }^{43}$ Akan tetapi hubungan pendukung juga bisa pecah apabila ada kasus atau mempertahankan pendiriannya secara semena-mena dan secara langsung menuduh kejelekan yang berakibat menjelekkan sesama anggota. Pada penyajian seni religi Hadrah hambatan yang sering dijumpai adalah waktu penyajiannya, transportasi dan cuaca. Waktu penyajian menurut masyarakat tidak menguntungkan, karena pagi harinya tidak bida bekerja. Untuk sarana transportasi kadang sulit didapatkan karena banyak yang tidak mau mengangkut pendukung dengan jumlah banyak. Penyajian seni religi Hadrah tidak dilakukan pada panggung permanen, apabila terjadi hujan pendukung harus mencari tempat berteduh sendiri. Begitu pula tempat penyajiannya kadang-kadang sulit untuk dijangkau dengan kendaraan bermotor.

Pengelolaan seni religi Hadrah agar tetap memiliki eksistensi pada masyarakat dilakukan dengan jalan iuran atau sumbangan secara sukarela melalui cara ini setiap anggota mengumpulkan uang untuk membeli perlengkapan berupa rebana, busana, dan sound system. Dari ketiga faktor tersebut, perlu adanya kewaspadaan dari seluruh pendukung agar tetap menjaga keutuhan jalinan. Apabila pendukung dapat mencegah adanya ketiga faktor maka pertumbuhan seni religi Hadrah dapat tetap memiliki eksistensi pada masyarakat. Dengan begitu keberadaan seni dapat berjalan dengan baik, apabila ditunjang sosial ekonomi, budaya dan religi masyarakat yang sesuai dengan sejarah peninggalan masa lampau. ${ }^{44}$ Perubahan merupakan tuntutan untuk menuju perubahan yang lebih baik, apabila perubahan itu merugikan maka harus ditinggalkan. ${ }^{45}$

Untuk mewujudkan seni religi Hadrah pada masyarakat dapat dilakukan melalui dua usaha yaitu internal dan eksternal. Agar pertumbuhan seni religi Hadrah dapat tumbuh dengan baik, maka usaha untuk pertumbuhan harus dapat berjalan dengan baik. Usaha yang pertumbuhannya dari dalam dan pertumbuhannya dipengaruhi oleh pendukung seni religi Hadrah salah satunya dengan melakukan regenerasi. Regenerasi merupakan alat untuk pertumbuhan dan mencegah adanya kemusnahan, agar seni religi Hadrah tetap memiliki eksistensi pada masyarakat Gresik. Untuk melakukan usaha ini seluruh pendukung seni religi Hadrah mengadakan latihan, baik itu rutin dilakukan di masjid atau silaturahmi ke rumah pendukung secara bergiliran. Selanjutnya, usaha eksternal yang merupakan usaha pertumbuhan oleh masyarakat sekitar. Usaha ini dilakukan dengan jalan mengadakan penyajian atau pertunjukan agar masyarakat mengenal atau tahu tentang keberadaan seni religi Hadrah dan mengikuti lomba atau penyajian seni religi Hadrah ke daerah lain.

Melalui dua usaha ini diharapkan dapat mewujudkan pertumbuhan tari, selain seni religi Hadrah tetap memiliki eksistensi pada masyarakat setempat dan dikenal oleh masyarakat luas. Begitu pula dengan pertumbuhan apabila pendukung seni religi Hadrah mengikuti event di luar Gresik, maka pendukung akan mendapatkan

43 Julia Day Howell, "Sufism and the Indonesian Islamic Revival," The Journal of Asian Studies 60, no. 3 (2001): 701-729.

44 Ibid.

${ }^{45}$ Jukka Jokilehto, "Preservation Theory Unfolding," Future Anterior: Journal of Historic Preservation, History, Theory, and Criticism 3, no. 1 (2012): 1-9. 
pengalaman banyak untuk menerapkan kreativitas baik itu gerak, iringan maupun lantunan irama sholawat yang dilakukan.

\section{Kesimpulan}

Keberadaan Hadrah di kabupaten Gresik merupakan kelanjutan Nabi Muhammad SAW dalam syiar agama Islam. Penyebaran agama Islam di tanah Jawa khususnya di Gresik, yaitu melalui media dakwah berupa seni dengan iringan sholawat. Syiar agama Islam di Gresik dilakukan oleh Sunan Maulana Malik Ibrahim dan Sunan Giri yang sampai saat ini dikenal sebagai pendiri kabupaten Gresik yang kini sudah menjadi Kota Gresik. Seiring bertambahnya waktu seni religi Hadrah yang dilakukan sebagai media dakwah semakin meluas ke seluruh wilayah tanah Jawa dengan iringan dan lantunan sholawat dan gerak yang disebut rodat. Pertumbuhan seni religi Hadrah semakin luas seiring dengan fungsinya sebagai perwujudan ekspresi rasa syukur kepada Allah dan Nabi Muhammad pada upacara haul, pernikahan dan khitan.

Untuk melestarikan seni religi Hadrah pada masyarakat dapat dilakukan melalui dua usaha yaitu internal dan eksternal. Usaha yang pertumbuhannya dari dalam dan pertumbuhannya dipengaruhi oleh pendukung seni religi Hadrah salah satunya dengan melakukan regenerasi. Selanjutnya, usaha eksternal yang merupakan usaha pertumbuhan oleh masyarakat sekitar. Usaha ini dilakukan dengan jalan mengadakan penyajian atau pertunjukan agar masyarakat mengenal atau tahu tentang keberadaan seni religi Hadrah dan mengikuti lomba atau penyajian seni religi Hadrah ke daerah lain.

\section{Referensi}

Ahimsa-Putra, Heddy Shri. Epistemologi Antropologi. Yogyakarta: Universitas Gadjah Mada Press, 1995.

Bakker, JWM. Filsafat Kebudayaan Sebuah Pengantar. Yogyakarta: Pustaka Filsafat Kanisius, 1984.

Barthel, Diane. "Historic Preservation : A Comparative Analyses." Sociological Forum 4, no. 1 (1989): 87-105.

Bhabha, Homi K. The Location of Culture. London: Routledge, 1994.

Bruinessen, Martin Van. "Studies of Sufism and the Sufi Orders in Indonesia." Die Welt des Islams 38, no. 2 (2011): 192-219.

Carrier, David. "Art and Its Preservation." The Journal of Aesthetics and Art Criticism 43, no. 3 (2006): 291.

Conway, Paul. "Preservation in the Age of Google : Digitization, Digital Preservation , and Dilemmas." The Library Quarterly: Information, Community, Policy 80, no. 1 (2015): 61-79. 
Feldman, Edmund Burke. Art as Image and Idea. New Jersey: Prentince Hall, 1967.

Geertz, Clifford. The Interpretation of Cultures. New York: Basic Book, 1973.

Hall, Stuart. Budaya Media Bahasa. Yogyakarta: Jalasutra, 2011.

Hawkesworth, C. J., P. A. Cawood, A.I.S. Kemp, C.D. Storey, and B. Dhuime. “A Matter of Preservation." Science 323, no. 5910 (2009): 49-50. http://www.sciencemag.org/cgi/doi/10.1126/science.1168549.

Howell, Julia Day. "Sufism and the Indonesian Islamic Revival." The Journal of Asian Studies 60, no. 3 (2001): 701-729.

Innocenti, Perla. "Preventing Digital Casualties: An Interdisciplinary Research for Preserving Digital Art." Leonardo 45, no. 5 (2012): 472-473.

Jokilehto, Jukka. "Preservation Theory Unfolding." Future Anterior: Journal of Historic Preservation, History, Theory, and Criticism 3, no. 1 (2012): 1-9.

Kayam, Umar. Seni, Tradisi, Masyarakat. Jakarta: Sinar Harapan, 1981.

Koentjaraningrat. Pengantar Antropologi (Pokok-Pokok Etnografi) II. Jakarta: Rineka Cipta, 1998.

Koentjaraningrat. Sejarah Teori Antropologi. Jakarta: UI Press, 1987.

Lintott, Sheila. "Preservation , Passivity , and Pessimism." Ethics and the Environment 16, no. 2 (2011): 95-114.

Malinowski. A Scientific Theory of Culture and Other Essays. New York: Oxford University Press, 1944.

Mallon, Sean. “Against Tradition." The Contemporary Pacific 22, no. 2 (2010): 362-381.

Mannani, Manijeh. “The Metaphysics of the Heart in the Sufi Poetry of Rumi.” Religion and Literature 42, no. 3 (2019): 161-168.

Millie, Julian. “Supplicating, Naming, Offering: 'Tawassul' in West Java." Journal of Southeast Asian Studies 39, no. 1 (2008): 107-122.

Muhaimin, A.G. "The Ritual Practice: Ibadat." In The Islamic Traditions of Cirebon. Indonesia: ANU Press, 2006.

Pace, Nicholas M., and Laura Zakaras. The Challenges of Preservation Book. RAND Corporation, 2013.

Parani, Yulianti. Penari Sebagai Sumber Daya Dalam Penataan Tari. Jakarta: Departemen Pendidikan dan Kebudayaan, 1986.

Rahardjo, M. Dawam. "Perceptions of Culture in the Islamic Movement: An Indonesian Perspective." Journalof Social Issues in Southeast Asia 7, no. 2 (1992): 248-273.

Royce, Anya Peterson. Antropologi Tari. Bandung: Sunan Ambu Press, 2007.

Thorslev, Peter L. "Preservation, Contemporary Art, and Architecture." Future Anterior: Journal of Historic Preservation, History, Theory, and Criticism 4, no. 2 (2007): 70-85. 
Agni Kusumawati, Setyo Yanuartuti

Wiyata, Latif. Carok Konflik Kekerasan Dan Harga Diri Orang Madura. Yogyakarta: LKIS, 2006. 


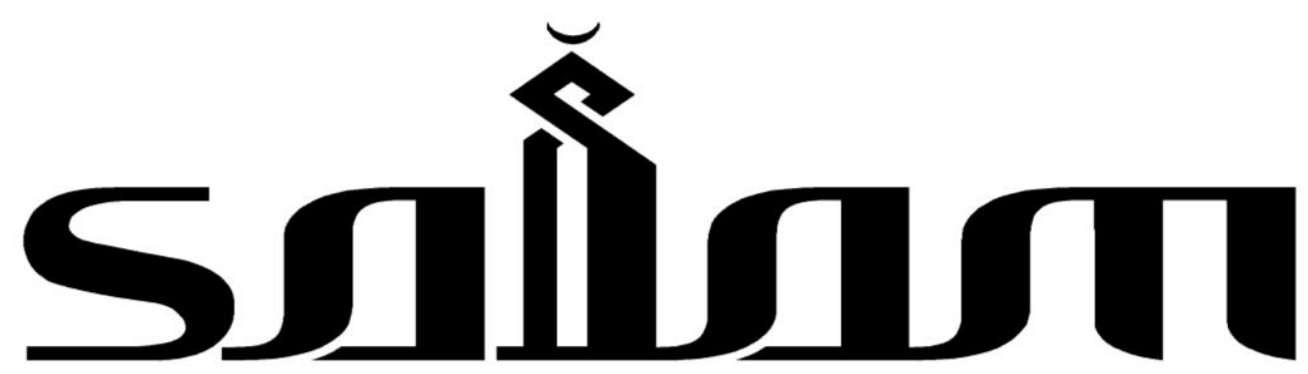

Jumnal Sosial dan Budaya Syar'i

\section{PEDOMAN TEKNIS PENULISAN BERKALA ILMIAH}

1. Artikel adalah benar-benar karya asli penulis, tidak mengandung unsur plagiasi, dan belum pernah dipublikasikan dan/atau sedang dalam proses publikasi pada media lain yang dinyatakan dengan surat pernyataan yang ditandatangani di atas meterai Rp 6000;

2. Naskah dapat berupa konseptual, resume hasil penelitian, atau pemikiran tokoh;

3. Naskah dapat berbahasa Indonesia, Inggris, Arab, maupun bahasa Rusia;

4. Naskah harus memuat informasi keilmuan dalam ranah ilmu hukum Positif;

5. Aturan penulisan adalah sebagai berikut:

a. Judul. Ditulis dengan huruf kapital, maksimum 12 kata diposisikan di tengah (centered);

b. Nama penulis. Ditulis utuh, tanpa gelar, disertai afiliasi kelembagaan dengan alamat lengkap, dan alamat e-mail;

c. Abstrak. Ditulis dalam bahasa Inggris dan Bahasa Indonesia antara 80-120 kata;

d. Sistematika penulisan naskah adalah sebagai berikut:

1) Judul;

2) Nama penulis (tanpa gelar akademik), nama dan alamat afiliasi penulis, dan e-mail;

3) Abstrak ditulis dalam dua bahasa, yaitu bahasa Indonesia dan Inggris, antara 80-120 kata;

4) Kata-kata kunci, antara 2-5 konsep yang mencerminkan substansi artikel;

5) Pendahuluan;

6) Sub judul (sesuai dengan keperluan pembahasan);

7) Penutup; dan

8) Pustaka Acuan (hanya memuat sumber-sumber yang dirujuk dan sedapat mungkin terbitan 10 tahun terakhir).

e. Ukuran kertas yang digunakan adalah kertas HVS 70 gram, ukuran A4, margin: atas $3,5 \mathrm{~cm}$, bawah $3.5 \mathrm{~cm}$, kiri $3,5 \mathrm{~cm}$, dan kanan $3,5 \mathrm{~cm}$;

f. Panjang Naskah antara 13 s.d. 15 halaman, spasi 1, huruf Palatino, ukuran 11;

g. Pengutipan kalimat. Kutipan kalimat ditulis secara langsung apabila lebih dari empat baris dipisahkan dari teks dengan jarak satu spasi dengan ukuran huruf 10 point. Sedangkan kutipan kurang dari empat baris diintegrasikan dalam teks, dengan tanda apostrof ganda di awal dan di akhir kutipan. Setiap kutipan diberi nomor. Sistem pengutipan adalah footnote (bukan bodynote atau endnote). Penulisan footnote menggunakan sistem turabian. Setiap artikel, buku, dan sumber lainnya yang dikutip harus tercantum dalam pustaka acuan;

h. Pengutipan Ayat Alquran dan Hadis. Ayat yang dikutip menyertakan keterangan ayat dalam kurung, dengan menyebut nama surah, nomor surah, dan nomor ayat, seperti (Q.s. al-Mu'min [40]: 43). Pengutipan Hadis menyebutkan nama perawi (H.r. al-Bukhārĩ dan Muslim) ditambah referensi versi cetak kitab Hadis yang dikutip. Hadis harus dikutip dari kitab-kitab Hadis standar (Kutub al-Tis'ah);

i. Cara pembuatan footnote. Footnote ditulis dengan font Palation size 9, untuk pelbagai sumber, antara lain: 
1) Buku: nama utuh penulis (tanpa gelar), judul buku (tempat terbit: penerbit, tahun terbit), cetakan, volume, juz, halaman. Contoh: Soerjono Soekanto, Pokok-pokok Sosiologi Hukum, (Jakarta: Rajawali Pers, 1986), h. 10.

2) Buku terjemahan, contoh: Roscoe Pound, Pengantar Filsafat Hukum: Buku III, diterjemahkan oleh Moh. Radjab, (Jakarta: Bharata, 1963), h. 15;

1) Jurnal, contoh: Nur Rohim, "Kontroversi Pembentukan Perppu No. 1 Tahun 2013 tentang mahkamah konstitusi dalam ranah kegentingan yang memaksa", dalam Jurnal Cita Hukum, Vol. 2, No. 1 (2014), h. 157.

2) Artikel sebagai bagian dari buku (antologi), contoh: Hikmahanto Juwana, "Penegakan Hukum dalam Kajian Law and Development: Problem dan Fundamen bagi Solusi Indonesia", dalam Muhammad Tahir Azhary, Beberapa Aspek Hukum Tata Negara, Hukum Pidana, dan Hukum Islam, (Jakarta: Kencana Prenada Media Gorup, 2012), h. 127.

3) Artikel dari internet, contoh: Ahmad Tholabi Kharlie, "Problem Yuridis RUU Syariah" dalam http://ahmadtholabi.com/2008/03/03/problem-yuridis-ruu-syariah, diunduh pada 20 Maret 2012.

4) Artikel dari majalah, contoh: Susilaningtias, "Potret Hukum Adat pada Masa Kolonial", dalam Forum Keadilan, No. 17, 20 Agustus 2006.

5) Makalah dalam seminar, contoh: Jimly Asshiddiqie, "Kedudukan Mahkamah Konstitusi dalam Struktur Ketatanegaraan Indonesia", Makalah disampaikan dalam Kuliah Umum Fakultas Hukum Universitas Sebelas Maret, Surakarta, pada 2 Maret 2004.

j. Pustaka Acuan: daftar pustaka acuan ditulis sesuai urutan abjad, nama akhir penulis diletakkan di depan. Contoh:

1) Buku, contoh: Soekanto, Soerjono, Pokok-pokok Sosiologi Hukum, Jakarta: Rajawali Pers, 1986.

2) Buku terjemahan, contoh: Pound, Roscoe, Pengantar Filsafat Hukum: Buku III, diterjemahakan oleh Moh. Radjab, Jakarta: Bharata, 1963.

3) Jurnal, contoh: Rohim, Nur, "Kontroversi Pembentukan Perppu No. 1 Tahun 2013 tentang mahkamah konstitusi dalam ranah kegentingan yang memaksa", dalam Jurnal Cita Hukum, Vol. 2, No. 1 (2014).

4) Artikel sebagai bagian dari buku, contoh: Juwana, Hikmahanto, "Penegakan Hukum dalam Kajian Law and Development: Problem dan Fundamen bagi Solusi Indonesia", dalam Muhammad Tahir Azhary, Beberapa Aspek Hukum Tata Negara, Hukum Pidana, dan Hukum Islam, Jakarta: Kencana Prenada Media Gorup, 2012.

5) Artikel yang dikutip dari internet, contoh: Kharlie, Ahmad Tholabi, "Problem Yuridis RUU Syariah" dalam http://ahmadtholabi.com/2008/03/03/problem-yuridis-ruu-syariah, diunduh pada 20 Maret 2012.

6) Majalah, contoh: Susilaningtias, "Potret Hukum Adat pada Masa Kolonial", dalam Forum Keadilan, No. 17, 20 Agustus 2006.

7) Makalah dalam seminar, contoh: Asshiddiqie, Jimly, "Kedudukan Mahkamah Konstitusi dalam Struktur Ketatanegaraan Indonesia", Makalah disampaikan dalam Kuliah Umum Fakultas Hukum Universitas Sebelas Maret, Surakarta, pada 2 Maret 2004.

k. Penutup: artikel ditutup dengan kesimpulan;

I. Biografi singkat: biografi penulis mengandung unsur nama (lengkap dengan gelar akademik), tempat tugas, riwayat pendidikan formal (S1, S2, S3), dan bidang keahlian akademik;

6. Setiap naskah yang tidak mengindahkan pedoman penulisan ini akan dikembalikan kepada penulisnya untuk diperbaiki.

7. Naskah sudah diserahkan kepada penyunting, selambat-lambatnya tiga bulan sebelum waktu penerbitan (April, Agustus. dan Desember) dengan mengupload pada laman OJS jurnal pada alamat http://journal.uinjkt.ac.id/index.php/salam atau dikirim langsung via e-mail ke: jurnal.salam@gmail.com atau nurrohimyunus@uinjkt.ac.id..] 


\section{Indexed by :}
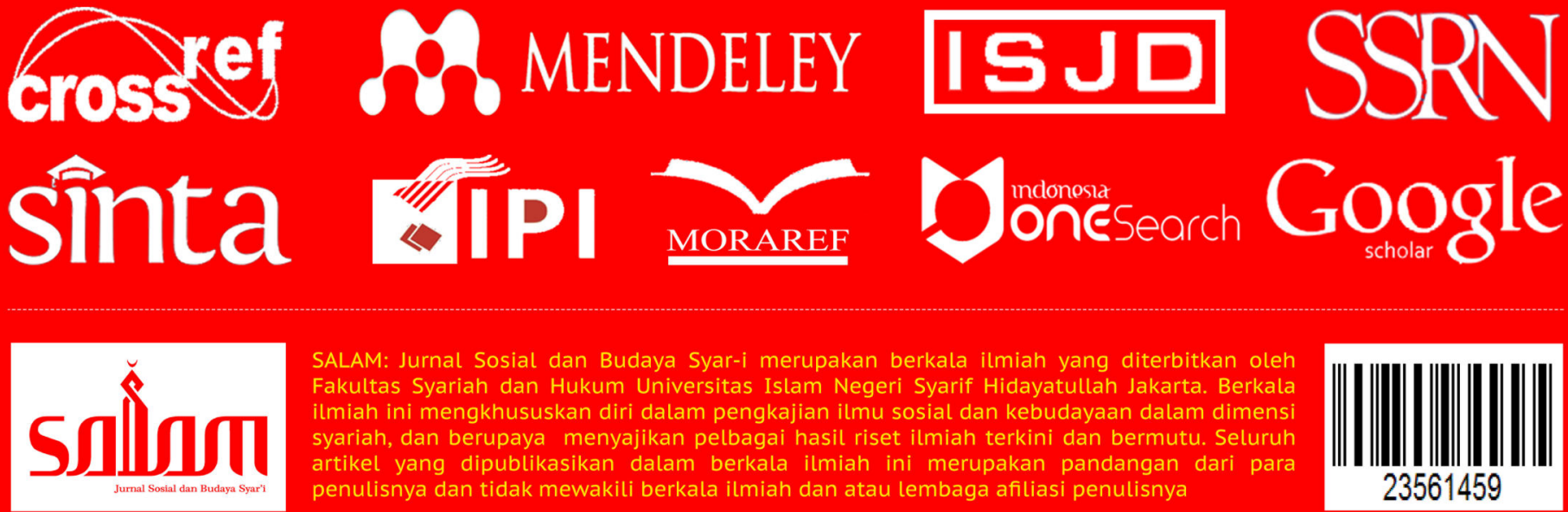

SALAM: Jurnal Sosial dan Budaya Syar-i merupakan berkala ilmiah yang diterbitkan oleh Fakultas Syariah dan Hukum Universitas Islam Negeri Syarif Hidayatullah Jakarta. Berkala ilmiah ini mengkhususkan diri dalam pengkajian ilmu sosial dan kebudayaan dalam dimensi syariah, dan berupaya menyajikan pelbagai hasil riset ilmiah terkini dan bermutu. Seluruh artikel yang dipublikasikan dalam berkala ilmiah ini merupakan pandangan dari para penulisnya dan tidak mewakili berkala ilmiah dan atau lembaga afiliasi penulisnya

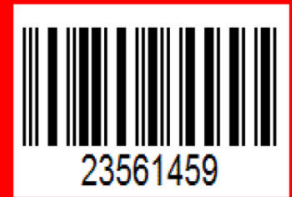

